\title{
Tolerability and efficacy of glycemic control with saxagliptin in older patients (aged $\geq 65$ years) with inadequately controlled type 2 diabetes mellitus
}

\section{Chetan S Karyekar \\ Shoba Ravichandran \\ Elsie Allen \\ Douglas Fleming \\ Robert Frederich}

Bristol-Myers Squibb, Princeton, NJ, USA
Correspondence: Chetan S Karyekar Director, Global Clinical Research, Bristol-Myers Squibb, Route 206 and Province Line Rd, Lawrenceville, NJ, 08543 USA

Tel + I 6092524573

Fax + I 60925278 II

Email chetan.karyekar@bms.com
This article was published in the following Dove Press journal:

Clinical Interventions in Aging

15 April 2013

Number of times this article has been viewed

Purpose: To assess safety and efficacy of saxagliptin in older patients with type 2 diabetes mellitus (T2DM).

Patients and methods: This was a post hoc analysis of pooled data from older patients ( $\geq 65$ years of age) from five 24 -week phase III trials: three studies of saxagliptin versus placebo as an add-on therapy to metformin, glyburide, or a thiazolidinedione; and two studies of saxagliptin versus placebo as monotherapy in drug-naïve patients. Separate analyses were conducted on one study of initial combination therapy with saxagliptin plus metformin versus metformin monotherapy in drug-naïve patients. The safety analysis population for the fivestudy pool included 428 patients $\geq 65$ years of age with baseline glycated hemoglobin $\left(\mathrm{HbA}_{1 \mathrm{c}}\right)$ $7.0 \%$ to $10.5 \%$ who received saxagliptin 2.5 or $5 \mathrm{mg}$ or placebo, and for the study of initial combination therapy included 69 patients $\geq 65$ years of age with baseline $\mathrm{HbA}_{1 \mathrm{c}} 8.0 \%$ to $12.0 \%$ who received saxagliptin $5 \mathrm{mg}$ in combination with metformin or metformin monotherapy. The primary efficacy endpoint was change from baseline $\mathrm{HbA}_{1 \mathrm{c}}$.

Results: In the five-study pool, the differences in the adjusted mean change from baseline $\mathrm{HbA}_{1 \mathrm{c}}$ among older patients receiving saxagliptin versus placebo were $-0.60 \%$ (95\% confidence interval [CI], $-0.99 \%$ to $-0.21 \%$ ) for saxagliptin $2.5 \mathrm{mg}$ and $-0.55 \%(-0.97 \%$ to $-0.14 \%)$ for saxagliptin $5 \mathrm{mg}$; in the initial combination study, the difference was $-1.22 \%(-2.27 \%$ to $-0.17 \%)$ among older patients receiving saxagliptin $5 \mathrm{mg}$ plus metformin versus metformin monotherapy. The results were generally similar in older and younger patients. Saxagliptin was well tolerated; the incidence and types of adverse events were similar for saxagliptin and comparators. Hypoglycemia was reported in $3.0 \%$ to $9.4 \%$ of patients receiving saxagliptin $(0 \%-8.0 \%$ for comparators) and was confirmed (finger stick glucose $\leq 50 \mathrm{mg} / \mathrm{dL}$, with associated symptoms) in $0 \%$ to $0.7 \%(0 \%-0.7 \%$ for comparators $)$; hypoglycemic episodes did not vary by age category and did not require medical intervention.

Conclusion: Saxagliptin was effective and well tolerated, with a low risk of hypoglycemia, when used as monotherapy, add-on therapy, or initial combination therapy with metformin in older patients with T2DM.

Keywords: clinical trial, dipeptidyl peptidase-4, DPP-4 inhibitor, hypoglycemia, metformin

\section{Introduction}

Elderly adults are becoming an increasingly large segment of the US population, ${ }^{1}$ and those aged $\geq 65$ years are almost seven times more likely to have diabetes compared with adults 20 to 44 years of age (27\% vs 4\%). ${ }^{2}$ Elderly adults with type 2 diabetes mellitus (T2DM) are more likely to have comorbid conditions, such as hypertension 
and coronary heart disease, than those without T2DM ${ }^{3}$ and are also likely to experience complications due to polypharmacy, mobility impairment and falls, cognitive impairment, chronic pain, and depression. ${ }^{4-8}$ These factors present challenges for glycemic control and successful management of T2DM in elderly patients.

There remains a need for treatment options that are well tolerated and efficacious in the geriatric population, especially because of the more challenging needs and higher risk of comorbid complications in these patients. ${ }^{5}$ Currently available and commonly employed therapies include the biguanide metformin, insulin, insulin secretagogues (sulfonylureas and meglitinides), thiazolidinediones, and incretin-based therapies (long-acting glucagon-like protein-1 [GLP-1] agonists and dipeptidyl peptidase-4 [DPP-4] inhibitors).

DPP-4 inhibitors have become widely accepted in clinical practice possibly because of their low risk of hypoglycemia, favorable adverse event (AE) profile, and once-daily oral administration. ${ }^{5,9}$ The general glycemic goal recommended by the American Diabetes Association and the European Association for the Study of Diabetes for most patients is $\mathrm{HbA}_{1 \mathrm{c}}<7 \%$, and the goal recommended by the American Association of Clinical Endocrinologists and American College of Endocrinology is $\mathrm{HbA}_{1 \mathrm{c}} \leq 6.5 \%,{ }^{10}$ but the goal for each patient should be individualized, based on such factors as life expectancy, comorbidities, and a history of severe hypoglycemia. ${ }^{5,10}$ Accordingly, the American Diabetes Association and European Association for the Study of Diabetes also recommend treatment options that avoid hypoglycemia, particularly in the elderly, ${ }^{5}$ given that conditions associated with age, such as renal impairment, polypharmacy, and cognitive dysfunction, may contribute to an increased risk of hypoglycemia. ${ }^{4,6-8}$ DPP-4 inhibitors are considered promising options in the elderly population. ${ }^{11}$ In recent analyses of patients $\geq 65$ years of age, DPP-4 inhibitors achieved glycemic control without increasing the risk of hypoglycemia or other AEs. ${ }^{12-16}$

Saxagliptin is a potent, selective DPP-4 inhibitor approved in 2009 by the US Food and Drug Administration (FDA) as an adjunct to diet and exercise, to improve glycemic control in adults with T2DM. ${ }^{17}$ Saxagliptin significantly improves glycemic control, as demonstrated by decreases in $\mathrm{HbA}_{1 \mathrm{c}}$, fasting plasma glucose (FPG), and postprandial glucose (PPG). ${ }^{18-24}$

In placebo-controlled phase III trials, saxagliptin has been assessed as monotherapy in drug-naïve patients, ${ }^{18,24}$ as an add-on therapy in patients who did not achieve adequate glycemic control on monotherapy with other oral antidiabetic drugs, ${ }^{19-21}$ and as initial combination therapy with metformin in drug-naïve patients. ${ }^{22}$ Each saxagliptin regimen in these trials was well tolerated; there was minimal risk of hypoglycemia with saxagliptin versus comparators except for a numerically higher incidence in the study of saxagliptin used as add-on to a sulfonylurea. ${ }^{21}$

Data on the safety and efficacy of saxagliptin in older patients are limited. One previous retrospective subgroup analysis of pooled data from five core placebo-controlled, phase III saxagliptin studies in patients aged $\geq 65$ years receiving saxagliptin $5 \mathrm{mg}$ has been reported. ${ }^{25}$ Saxagliptin is approved to be used at doses of 2.5 and $5 \mathrm{mg}$ in the United States and at $5 \mathrm{mg}$ in many other countries. In addition, saxagliptin is approved for use as an add-on agent or for first-line therapy. ${ }^{26}$ To provide relevant clinical-use data, the current post hoc analysis assessed efficacy and safety outcomes with saxagliptin $2.5 \mathrm{mg}$ and $5 \mathrm{mg}$, in the subgroup of patients aged $\geq 65$ years, from the five placebo-controlled core saxagliptin studies as well as an additional core study evaluating saxagliptin used as initial combination therapy with metformin versus metformin monotherapy in drug-naïve patients. The five placebo-controlled trials, which shared similar methodology, were pooled to achieve a large sample of older patients for statistical analysis. The remaining study was assessed separately due to differences in methodology (including the lack of a placebo control); it will be referred to subsequently as the initial combination study.

\section{Material and methods Study designs}

The core saxagliptin phase III program consisted of a set of multicenter, randomized, double-blind, 24-week trials (Table 1). Saxagliptin, at daily doses of 2.5 and $5 \mathrm{mg}$, was assessed in two placebo-controlled trials of monotherapy in drug-naïve patients (ClinicalTrials.gov identifiers NCT00121641, NCT00316082) ${ }^{18,24}$ and in three placebocontrolled trials of add-on therapy in patients who did not achieve adequate glycemic control on monotherapy with metformin (immediate-release [IR] formulation) 500 to $2500 \mathrm{mg}$ (NCT00121667), a thiazolidinedione (pioglitazone 30 or $45 \mathrm{mg}$ or rosiglitazone 4 or $8 \mathrm{mg}$ ) (NCT00295633), or a sulfonylurea (glyburide at a submaximal dose of $7.5 \mathrm{mg}$, uptitrated to $15 \mathrm{mg}$ per protocol in the placebo arm as needed) (NCT00313313). ${ }^{19-21}$ In the add-on studies, patients remained on their initial metformin, thiazolidinedione, or sulfonylurea therapy as saxagliptin or placebo was initiated. In the initial combination study, saxagliptin $5 \mathrm{mg}$ was assessed as initial combination therapy with metformin IR 500-2000 mg 
Table I Pivotal phase III Studies (24 Weeks) of saxagliptin in patients with type 2 diabetes mellitus

\begin{tabular}{|c|c|c|c|c|c|}
\hline \multirow[t]{2}{*}{ Study } & \multirow[t]{2}{*}{ Entry conditions } & \multirow{2}{*}{$\begin{array}{l}\text { Number of patients } \\
\text { aged } \geq 65 \text { years }\end{array}$} & \multirow{2}{*}{$\begin{array}{l}\text { Number of patients } \\
\text { aged }<65 \text { years }\end{array}$} & \multicolumn{2}{|l|}{ Treatment groups } \\
\hline & & & & Saxagliptin & Comparator \\
\hline \multicolumn{6}{|c|}{ SAXA vs PBO as monotherapy in drug-naïve patients } \\
\hline \multirow[t]{2}{*}{ NCT00 $\left.2164\right|^{18}$} & $\mathrm{HbA}_{\mathrm{Ic}} 7 \%-\mathrm{I0} \%(\mathrm{n}=40 \mathrm{I})^{\mathrm{a}}$ & 63 & 338 & $2.5,5$, or $10 \mathrm{mg} Q D$ & PBO \\
\hline & & & & $2.5 \mathrm{mg}$ QD & PBO \\
\hline \multirow[t]{2}{*}{ NCT00316082 24} & $\mathrm{HbA}_{\mathrm{Ic}} 7 \%-10 \%(\mathrm{n}=365)$ & 64 & 301 & $2.5 / 5 \mathrm{mg} \mathrm{QD}^{\mathrm{b}}$ & PBO \\
\hline & & & & $5 \mathrm{mg}$ QD & PBO \\
\hline \multicolumn{6}{|c|}{ SAXA vs PBO as add-on to continuing therapy with another oral antidiabetic drug } \\
\hline NCT00I $21667^{20}$ & MET (I500-2550 mg/d $\leq 8 \mathrm{wk})$ & 117 & 626 & $2.5,5$, or $10 \mathrm{mg}$ & $\mathrm{PBO}+\mathrm{MET}$ \\
\hline (add-on to MET) & $\mathrm{HbA}_{\mathrm{Ic}} 7 \%-10 \%(\mathrm{n}=743)$ & & & $\mathrm{QD}+\mathrm{MET}$ & \\
\hline NCT0029563319 & TZD (stable dose) ${ }^{c} \geq 12 \mathrm{wk}$ & 87 & 478 & 2.5 or $5 \mathrm{mg}$ & $\mathrm{PBO}+\mathrm{TZD}^{\mathrm{c}}$ \\
\hline (add-on to TZD) & $\mathrm{HbA}_{\mathrm{lc}} 7 \%-10.5 \%(\mathrm{n}=565)$ & & & QD + TZD & \\
\hline NCT003।33I3 21 & SU (submaximal) $^{d} \geq 2$ mo & 137 & 631 & 2.5 or $5 \mathrm{mg}$ & $\mathrm{PBO}+\mathrm{SU}^{\mathrm{d}}$ \\
\hline (add-on to SU) & $\mathrm{HbA}_{\mathrm{Ic}} 7.5 \%-10.0 \%(\mathrm{n}=768)$ & & & $\mathrm{QD}+\mathrm{SU}^{\mathrm{d}}$ & \\
\hline \multicolumn{6}{|c|}{ SAXA as initial combination therapy with MET vs MET monotherapy in drug-naïve patients } \\
\hline \multirow[t]{2}{*}{ NCT003270I $5^{22}$} & $\mathrm{HbA}_{\mathrm{Ic}} 8.0 \%-12.0 \%(\mathrm{n}=1306)$ & 166 & 1140 & 10 mg QD & $\mathrm{PBO}+\mathrm{MET}^{\mathrm{e}}$ \\
\hline & & & & 5 or $10 \mathrm{mg}$ QD + $\mathrm{MET}^{\mathrm{e}}$ & \\
\hline
\end{tabular}

Notes: anly patients from the main treatment cohort of this trial were included in the present analysis; data from the open-label cohort (older patients treated with saxagliptin $10 \mathrm{mg} Q D ; n=2$ ) were excluded; beligibility for titration from 2.5 to $5 \mathrm{mg} / \mathrm{d}$ evaluated at weeks 4,8 , and I2; these patients (age $\geq 65$ years; $\mathrm{n}=7 \mathrm{I}$ and $\mathrm{n}=12$, respectively) are included in the safety analyses but not the efficacy analyses; 'stable fixed dosage of pioglitazone 30 or $45 \mathrm{mg} / \mathrm{d}$ or rosiglitazone 4 or $8 \mathrm{mg} / \mathrm{d}$; switch from rosiglitazone to pioglitazone permitted as needed; ' glyburide $7.5 \mathrm{mg} / \mathrm{d}$; uptitration to $10,12.5$, or $15 \mathrm{mg} / \mathrm{d}$ permitted if mean fasting glucose $\geq 100 \mathrm{mg} / \mathrm{dL}$ or $\geq 95 \mathrm{mg} / \mathrm{dL}$ at week 2 or 4; uptitration not permitted after down-titration for hypoglycemia; no titration after rescue with MET; eMET titration: forced 500 to 1000 mg/d at week I, then elective, weekly, to a maximum $2000 \mathrm{mg} / \mathrm{d}$, to achieve mean fasting glucose $\leq 110 \mathrm{mg} / \mathrm{dL}$.

Abbreviations: $\mathrm{HbA}_{I c}$, glycated hemoglobin; MET, metformin; PBO, placebo; QD, once daily; SAXA, saxagliptin; SU, sulfonylurea; TZD, thiazolidinedione.

versus metformin monotherapy in drug-naïve patients (NCT00327015). ${ }^{22}$ One of the monotherapy studies ${ }^{24}$ also included a treatment arm in which saxagliptin was titrated from 2.5 to $5 \mathrm{mg}$; the other monotherapy study, ${ }^{18}$ the metformin add-on study, ${ }^{20}$ and the initial combination study ${ }^{22}$ also included treatment arms in which saxagliptin was given at $10 \mathrm{mg}$.

Individual study methodology has been previously reported. ${ }^{18-22,24}$ Briefly, the study populations included men and women aged 18 to 77 years with T2DM and inadequate glycemic control, a fasting C-peptide concentration $\geq 1 \mathrm{ng} / \mathrm{mL}$, and a body mass index (BMI) $\leq 40 \mathrm{~kg} / \mathrm{m}^{2}\left(\leq 45 \mathrm{~kg} / \mathrm{m}^{2}\right.$ in the study of saxagliptin added on to thiazolidinedione ${ }^{19}$ ). Patients were treated on an outpatient basis. Exclusion criteria were similar across the studies. ${ }^{18-22,24}$ Rescue therapy was initiated if patients did not meet prespecified and progressively stringent glycemic goals while on study medication (FPG $>240 \mathrm{mg} / \mathrm{dL}$ at week 4 or $6 ;>220 \mathrm{mg} / \mathrm{dL}$ at week $8 ;>200 \mathrm{mg} / \mathrm{dL}$ at week $12,16,20$, or 24$)$. The study protocols and patient informed consent were approved by the respective institutional review board. The studies were conducted in accordance with Good Clinical Practice guidelines and the Declaration of Helsinki.

\section{Efficacy and safety parameters}

Efficacy results were assessed across all six studies. ${ }^{18-22,24}$ The primary efficacy endpoint was change in $\mathrm{HbA}_{1 \mathrm{c}}$ from baseline to week 24 . The secondary efficacy endpoints included changes in FPG from baseline to week 24, in PPG at 120 minutes (PPG-120) following a $75 \mathrm{~g}$ oral glucose tolerance test (OGTT), and in PPG area under the curve from 0 to 180 minutes (PPG-AUC ${ }_{0-180}$ ) in the OGTT; the proportion of patients achieving a therapeutic glycemic target $\left(\mathrm{HbA}_{1 \mathrm{c}}<7.0 \%\right)$ was also reported. The safety and tolerability assessments included overall AEs, serious AEs (SAEs), and discontinuations due to AEs. Hypoglycemic AEs, including all reported cases of hypoglycemia and confirmed hypoglycemia (defined as finger stick glucose value $\leq 50 \mathrm{mg} / \mathrm{dL}$ associated with symptoms), were recorded.

\section{Statistical methods}

For the present post hoc analysis, the subgroup analysis of these six core studies, efficacy and safety outcomes were analyzed in older patients with T2DM ( $\geq 65$ years of age); the data for younger patients ( $<65$ years of age) are presented for reference. The age-categorized data from the placebocontrolled trials of saxagliptin as monotherapy and as add-on therapy are pooled; data from the initial combination study are presented separately.

The overall efficacy and safety results have previously been reported for all six studies. ${ }^{18-22,24}$ The present post hoc analysis of outcomes in older patients included only data from patients receiving saxagliptin at the currently approved doses of 2.5 or $5 \mathrm{mg}$. Data from patients randomized to 
treatment with saxagliptin $2.5 \mathrm{mg}$ with possible titration to $5 \mathrm{mg}^{24}(\mathrm{n}=12)$ were excluded from the efficacy but not the safety analyses because the doses were not constant across the evaluation period; data from patients receiving saxagliptin $10 \mathrm{mg}^{18,20,22}$ were excluded from the efficacy and safety analyses because $10 \mathrm{mg}$ is not an FDA-approved dose. A baseline plus one or more postbaseline measurement(s) were required for inclusion in the efficacy analysis. Safety analyses included patients who received one or more dose(s) of study medication.

In an intent-to-treat analysis of the five pooled studies, the evaluation for change from baseline to week 24 in $\mathrm{HbA}_{1 \mathrm{c}}$, FPG, PPG-AUC ${ }_{0-180}$, and PPG-120 used analysis of covariance (ANCOVA), with treatment, subgroup, study, and treatmentby-subgroup as factors and baseline as a covariate. A nominal test was performed for the treatment-by-subgroup interactions including treatment-by-age interaction. Two-sided 95\% confidence intervals (CIs) are presented for the within-group adjusted mean change from baseline to week 24 and for the difference between the adjusted mean change from baseline to week 24 with the saxagliptin regimen minus that of the comparator regimen. For the proportion of patients who achieved $\mathrm{HbA}_{1 \mathrm{c}}<7.0 \%, 95 \% \mathrm{CIs}$ are presented for the difference versus comparators, using an exact $\mathrm{CI}$ for the initial combination study and the Mantel-Haenszel CI for the risk difference for the five pooled studies. Missing data were imputed using last observation carried forward (LOCF) methodology. In patients who required rescue medication, the last value before rescue medication was used in the analysis.

\section{Results}

\section{Study population}

Patient disposition for each of the individual studies has been described previously. ${ }^{18-22,24}$ There were a total of 468 older patients (16.5\% of the overall study population) in the five pooled placebo-controlled studies of saxagliptin as monotherapy and add-on therapy, and 166 older patients ( $12.7 \%$ of the overall study population) in the study of saxagliptin as initial combination therapy with metformin. In the pooled studies and initial combination study, the majority of older patients were aged 65 to 75 years with only 23 and 16 patients, respectively, aged $\geq 75$ years. Because of treatment arm exclusions, as detailed in the Methods, the safety analysis included 428 older patients from the five pooled studies and 69 older patients from the initial combination study; 416 older patients in the five pooled studies and 69 from the initial combination study were included in the efficacy analyses. In all, 341/428 (79.7\%) older patients in the pooled studies and 58/69 (84.1\%) in the initial combination study completed 24 weeks of treatment.

Baseline demographic and clinical characteristics are shown in Tables 2A and B. In the five-study pool and the initial combination study, the mean age of the older patients was 69 to 70 years. The mean duration of T2DM was 7.2 to 7.3 years in the pooled studies and 0.8 to 1.4 years in the initial combination study. Patients in the initial combination study had higher glycemic values than those in the pooled studies $\left(\mathrm{HbA}_{1 \mathrm{c}}: 8.9 \%-9.5 \%\right.$ vs $7.9 \%-8.2 \%$; FPG: $192.5-207.2 \mathrm{mg} / \mathrm{dL}$ vs $161.2-171.9 \mathrm{mg} / \mathrm{dL})$. In the pooled population, mean creatinine clearance rates were 80 to $84 \mathrm{~mL} / \mathrm{min}$ in older patients and 118 to $119 \mathrm{~mL} / \mathrm{min}$ in younger patients. In the initial combination study, the mean creatinine clearance rates were 82 to $83 \mathrm{~mL} / \mathrm{min}$ in older patients and 119 to $120 \mathrm{~mL} / \mathrm{min}$ in younger patients. Concomitant medications were widely used at baseline. In the pooled population, $58 \%$ to $69 \%$ of older patients and $40 \%$ to $41 \%$ of younger patients were studied on a background of $\geq 5$ medications. In the initial combination study, the majority of patients in both age groups were studied on a background of $\geq 2$ concomitant medications. Other demographic and baseline characteristics were similar across treatment groups.

\section{Efficacy}

\section{Change in glycated hemoglobin}

In the five-study pooled analysis, the mean baseline $\mathrm{HbA}_{1 \mathrm{c}}$ ranged from $7.91 \%$ to $8.24 \%$ and was similar between the saxagliptin $2.5 \mathrm{mg}$ and $5 \mathrm{mg}$ groups and between age groups (Table 3A). The week 24 adjusted mean changes from baseline $\mathrm{HbA}_{1 \mathrm{c}}$ were $-0.78 \%$ and $-0.73 \%$ for older patients taking saxagliptin 2.5 and $5 \mathrm{mg}$ and were slightly smaller in the younger subgroup. The differences in the adjusted mean changes from baseline $\mathrm{HbA}_{1 \mathrm{c}}$ with saxagliptin minus that of placebo were $-0.60 \%$ (95\% CI, $-0.99 \%$ to $-0.21 \%$ ) and $-0.55 \%(95 \% \mathrm{CI},-0.97 \%$ to $-0.14 \%)$ for older patients taking saxagliptin 2.5 and $5 \mathrm{mg}$. There was no evidence for a treatment-by-age interaction for $\mathrm{HbA}_{1 \mathrm{c}}$ in the five-study $\operatorname{pool}(P=0.88)$.

In the initial combination study, the adjusted mean changes from baseline $\mathrm{HbA}_{1 \mathrm{c}}$ at week 24 for saxagliptin $5 \mathrm{mg}$ plus metformin were similar in the older $(-2.48 \%)$ and younger $(-2.55 \%)$ groups (Table $3 \mathrm{~B})$. The metforminsubtracted adjusted mean change from baseline with saxagliptin $5 \mathrm{mg}$ plus metformin was numerically larger in older versus younger participants (treatment-by-age interaction, $P=0.14)$. 
Table 2A Baseline demographic and clinical characteristics of older and younger patients with type 2 diabetes mellitus from five pooled studies of saxagliptin vs placebo as monotherapy and as add-on therapy ${ }^{18-21,24}$

\begin{tabular}{|c|c|c|c|c|c|c|}
\hline \multirow[t]{2}{*}{ Characteristic } & \multicolumn{3}{|l|}{ Age $\geq 65$ years } & \multicolumn{3}{|l|}{ Age $<65$ years } \\
\hline & $\begin{array}{l}\text { SAXA } 2.5 \mathrm{mg} \\
\mathrm{n}=149\end{array}$ & $\begin{array}{l}\text { SAXA } 5 \mathrm{mg} \\
\mathrm{n}=142\end{array}$ & $\begin{array}{l}\text { PBO } \\
n=137\end{array}$ & $\begin{array}{l}\text { SAXA } 2.5 \mathrm{mg} \\
\mathrm{n}=733\end{array}$ & $\begin{array}{l}\text { SAXA } 5 \mathrm{mg} \\
\mathrm{n}=740\end{array}$ & $\begin{array}{l}\text { PBO } \\
n=662\end{array}$ \\
\hline Age $(y)$, mean (SD) & $69.1(3.2)$ & $69.0(3.4)$ & $69.1(3.2)$ & $51.8(8.2)$ & $51.5(8.6)$ & $51.7(9.0)$ \\
\hline \multicolumn{7}{|l|}{ Gender, n (\%) } \\
\hline Male & $67(45.0)$ & $69(48.6)$ & 7I (5I.8) & $355(48.4)$ & $358(48.4)$ & $315(47.6)$ \\
\hline Female & $82(55.0)$ & $73(51.4)$ & $66(48.2)$ & $378(51.6)$ & $382(51.6)$ & $347(52.4)$ \\
\hline \multicolumn{7}{|l|}{ Race, n (\%) } \\
\hline White & $108(72.5)$ & $98(69.0)$ & 97 (70.8) & $495(67.5)$ & $50 \mathrm{I}(67.7)$ & $438(66.2)$ \\
\hline Asian & $2 I(14.1)$ & $18(12.7)$ & $18(13.1)$ & $133(18.1)$ & I37 (I8.5) & $120(|8|)$. \\
\hline Black/African American & $4(2.7)$ & $6(4.2)$ & $3(2.2)$ & $26(3.5)$ & $40(5.4)$ & $28(4.2)$ \\
\hline Other & $16(10.7)$ & $20(14.1)$ & $19(13.9)$ & $79(10.8)$ & $62(8.4)$ & $76(11.5)$ \\
\hline Weight (kg), mean (SD) & $78.5(17.1)$ & $77.5(17.1)$ & $78.2(15.4)$ & $83.4(18.8)$ & $83.7(19.2)$ & $82.3(19.3)$ \\
\hline BMI $\left(\mathrm{kg} / \mathrm{m}^{2}\right)$, mean $(\mathrm{SD})$ & $29.7(4.8)$ & $29.2(4.3)$ & $29.2(4.5)$ & $30.6(5.2)$ & $30.5(5.1)$ & $30.5(5.1)$ \\
\hline T2DM duration (yr), mean (SD) & $7.3(6.0)$ & $7.3(7.4)$ & $7.2(6.9)$ & $4.8(5.0)$ & $4.6(4.7)$ & $5.0(5.0)$ \\
\hline $\mathrm{HbA}_{\mathrm{Ic}}(\%)$, mean $(\mathrm{SD})$ & $8.1(1.0)$ & $8.1(0.9)$ & $7.9(0.8)$ & $8.2(1.0)$ & $7.9(1.0)$ & $8.2(1.0)$ \\
\hline$<8.0 \%, \mathrm{n}(\%)$ & 74 (49.7) & $72(50.7)$ & $84(6 \mid .3)$ & $334(45.6)$ & $310(41.9)$ & $291(44.0)$ \\
\hline$\geq 8.0 \%$ to $<9.0 \%, \mathrm{n}(\%)$ & $50(33.6)$ & $43(30.3)$ & $32(23.4)$ & $238(32.5)$ & $262(35.4)$ & $219(33.1)$ \\
\hline$\geq 9.0 \%, \mathrm{n}(\%)$ & $25(16.8)$ & $27(19.0)$ & $21(15.3)$ & $160(21.8)$ & $166(22.4)$ & $152(23)$ \\
\hline FPG (mg/dL), mean (SD) & $163.3(42.3)$ & $161.2(35.9)$ & I62.6 (4I.4) & I $70.5(45.0)$ & I7I.9 (46.4) & $17 \mid .5(45.1)$ \\
\hline $\mathrm{CrCl}, \mathrm{mL} / \mathrm{min}$, mean (SD) & $83.7(25.11)$ & $80.0(21.14)$ & $79.9(18.86)$ & II $8.4(37.16)$ & I 19.2 (39.28) & I I $8.3(40.48)$ \\
\hline \multicolumn{7}{|c|}{ Number of concomitant medications, ${ }^{*} \mathrm{n}(\%)$} \\
\hline 0 & $4(2.7)$ & $2(1.4)$ & I (0.7) & $29(4.0)$ & $34(4.6)$ & $18(2.7)$ \\
\hline 1 & $12(8.1)$ & $7(4.9)$ & $8(5.8)$ & $89(12.1)$ & $88(11.9)$ & $84(12.7)$ \\
\hline 2 & $12(8.1)$ & $18(12.7)$ & $6(4.4)$ & $114(15.6)$ & II $5(15.5)$ & $98(14.8)$ \\
\hline 3 & $18(12.1)$ & $23(16.2)$ & $9(6.6)$ & $101(13.8)$ & $119(16.1)$ & $98(14.8)$ \\
\hline 4 & $14(9.4)$ & $10(7.0)$ & $18(13.1)$ & $100(13.6)$ & $89(12.0)$ & $94(14.2)$ \\
\hline$\geq 5$ & $89(59.7)$ & $82(57.7)$ & $95(69.3)$ & $300(40.9)$ & 295 (39.9) & $270(40.8)$ \\
\hline
\end{tabular}

Notes: *Medication with $\geq \mathrm{I}$ dose taken between the first and last day of double-blind treatment; could include diabetes or nondiabetes medications (eg, antihypertensive medication, analgesics/antipyretics, antihyperglycemic medication).

Abbreviations: BMI, body mass index; $\mathrm{CrCl}$, creatinine clearance; FPG, fasting plasma glucose; HbA saxagliptin; SD, standard deviation; T2DM, type 2 diabetes mellitus.

\section{Other glycemic outcome measures}

For both older and younger subjects, reductions from baseline to week 24 in PPG-AUC ${ }_{0-180}$ and PPG-120 and the percentage of patients achieving $\mathrm{HbA}_{1 \mathrm{c}}<7 \%$ at week 24 were greater with saxagliptin than with placebo, in the pooled studies. However, the adjusted mean change from baseline FPG for older patients receiving saxagliptin $2.5 \mathrm{mg}(-7.6 \mathrm{mg} / \mathrm{dL})$ was associated with a $95 \% \mathrm{CI}$ that spanned zero $(-17.4,2.2)$, although it was directionally consistent with that in younger patients $(-13.1 \mathrm{mg} / \mathrm{dL})$ (Table 3A). In the initial combination study, the metformin-subtracted reductions from baseline to week 24 in FPG, PPG-AUC ${ }_{0-180}$, and PPG-120 were numerically greater with saxagliptin plus metformin in the older population than those observed in the younger patients. The difference in the proportions of patients achieving $\mathrm{HbA}_{1 \mathrm{c}}<7 \%$ with saxagliptin plus metformin versus metformin alone was similar in magnitude in older $(18.7 \%)$ and younger (19.2\%) patients (Table 3B), but the older subgroup had a $95 \%$ CI which spanned zero $(-5.7 \%, 40.6 \%)$.

\section{Safety and tolerability}

Overall, saxagliptin was generally well tolerated as monotherapy or combination therapy in older patients. In both the five-study pool and the initial combination study, the incidence and types of AEs were similar for saxagliptin and the placebo and metformin comparators. The overall incidence of AEs and the specific AEs occurring in $\geq 5 \%$ of patients in any treatment group in the pooled studies and in the initial combination study are shown in Tables 4A and 4B, respectively.

In the pooled analysis, no SAE in the older subgroup was considered by the investigator to be related to saxagliptin treatment. In the initial combination study, one saxagliptin patient in the older subgroup had a treatment-related SAE (presumed overdose, without hypoglycemia or other symptoms), which led to discontinuation from the study on grounds of poor compliance. There were two deaths in the older subgroup (one patient receiving saxagliptin $2.5 \mathrm{mg}$ in the pooled analysis [car accident owing to 
Table 2B Baseline demographic and clinical characteristics of older and younger patients with type 2 diabetes mellitus from a study of saxagliptin $5 \mathrm{mg}$ as initial combination therapy with metformin vs metformin monotherapy ${ }^{22}$

\begin{tabular}{|c|c|c|c|c|}
\hline \multirow[t]{2}{*}{ Characteristic } & \multicolumn{2}{|l|}{ Age $\geq 65$ years } & \multicolumn{2}{|l|}{ Age $<65$ years } \\
\hline & $\begin{array}{l}\text { SAXA + MET } \\
\mathrm{n}=33\end{array}$ & $\begin{array}{l}\text { MET } \\
n=36\end{array}$ & $\begin{array}{l}\text { SAXA + MET } \\
n=287\end{array}$ & $\begin{array}{l}\text { MET } \\
n=292\end{array}$ \\
\hline Age (y), mean (SD) & $68.6(2.8)$ & $69.6(4.0)$ & $50.0(9.2)$ & $49.6(9.2)$ \\
\hline \multicolumn{5}{|l|}{ Gender, n (\%) } \\
\hline Male & $10(30.3)$ & $14(38.9)$ & $155(54.0)$ & $149(5 \mid .0)$ \\
\hline Female & $23(69.7)$ & $22(61.1)$ & $132(46.0)$ & $143(49.0)$ \\
\hline \multicolumn{5}{|l|}{ Race, n (\%) } \\
\hline White & $30(90.9)$ & 33 (91.7) & $216(75.3)$ & $218(74.7)$ \\
\hline Asian & I (3.0) & I (2.8) & $50(17.4)$ & $5 I(\mid 7.5)$ \\
\hline Black/African American & 0 & 0 & $7(2.4)$ & $4(1.4)$ \\
\hline Other & $2(6.1)$ & $2(5.6)$ & $14(4.9)$ & $19(6.5)$ \\
\hline Weight (kg), mean (SD) & $79.6(12.9)$ & $79.4(16.0)$ & $82.3(16.6)$ & $83.2(17.7)$ \\
\hline BMI $\left(\mathrm{kg} / \mathrm{m}^{2}\right)$, mean $(\mathrm{SD})$ & $30.1(3.6)$ & $29.4(3.9)$ & $29.9(4.5)$ & $30.3(5.0)$ \\
\hline T2DM duration (y), mean (SD) & $0.8(1.7)$ & $\mathrm{I} .4(\mathrm{I} .9)$ & $2.1(3.8)$ & I.8 (3.3) \\
\hline $\mathrm{HbA}_{\mathrm{Ic}}(\%)$, mean (SD) & $9.2(1.4)$ & $8.9(1.1)$ & $9.4(1.2)$ & $9.5(1.3)$ \\
\hline$<8.0 \%, \mathrm{n}(\%)$ & $5(15.2)$ & $5(13.9)$ & $26(9.1)$ & $32(11.0)$ \\
\hline$\geq 8.0 \%$ to $<9.0 \%, \mathrm{n}(\%)$ & $12(36.4)$ & $17(47.2)$ & $80(27.9)$ & $81(27.7)$ \\
\hline$\geq 9.0 \%, \mathrm{n}(\%)$ & $16(48.5)$ & $14(38.9)$ & $179(62.4)$ & $178(6 \mid .0)$ \\
\hline FPG $(\mathrm{mg} / \mathrm{dL})$, mean $(\mathrm{SD})$ & $207.2(57.3)$ & $192.5(56.0)$ & $197.9(56.5)$ & $198.9(59.0)$ \\
\hline $\mathrm{CrCl}(\mathrm{mL} / \mathrm{min})$, mean (SD) & $82.9(\mid 8.09)$ & $81.9(20.28)$ & I $20.2(36.40)$ & II9.I (37.43) \\
\hline \multicolumn{5}{|c|}{ Number of concomitant medications*, n (\%) } \\
\hline 0 & $5(15.2)$ & $8(22.2)$ & $82(28.6)$ & $57(19.5)$ \\
\hline 1 & $5(15.2)$ & $5(\mid 3.9)$ & 7I (24.7) & $78(26.7)$ \\
\hline 2 & $7(2 \mid .2)$ & $7(19.4)$ & $58(20.2)$ & $60(20.5)$ \\
\hline 3 & $6(18.2)$ & $8(22.2)$ & $34(1 \mathrm{l} .8)$ & $36(12.3)$ \\
\hline 4 & $4(12.1)$ & $2(5.6)$ & $8(2.8)$ & $27(9.2)$ \\
\hline$\geq 5$ & $6(18.2)$ & $6(16.7)$ & $34($ (II.8) & $34($ (II.6) \\
\hline
\end{tabular}

Notes: *Medication taken during lead-in or double-blind treatment; could include diabetes or nondiabetes medications (eg, antihypertensive medication, analgesics/ antipyretics, antihyperglycemic medication).

Abbreviations: BMI, body mass index; $\mathrm{CrCl}$, creatinine clearance; FPG, fasting plasma glucose; HbA ${ }_{\mathrm{lc}}$ glycated hemoglobin; MET, metformin; PBO, placebo; SAXA, saxagliptin; SD, standard deviation; T2DM, type 2 diabetes mellitus.

weather/road conditions]; one patient receiving metformin monotherapy in the initial combination study [apparent congestive heart failure]); neither event was considered treatment-related.

In the pooled studies, the incidence of confirmed hypoglycemia was $0.7 \%$ and $0 \%$ with saxagliptin 2.5 and $5 \mathrm{mg}$, and $0.7 \%$ with placebo in older patients. The incidence of all reported hypoglycemia in the older subgroup was $9.4 \%$ and $6.3 \%$ with saxagliptin 2.5 and $5 \mathrm{mg}$, respectively, and $8.0 \%$ with placebo. In a separate pooled analysis excluding the study of add-on to the sulfonylurea glyburide, which carries a known risk of hypoglycemia, the incidence of reported hypoglycemia in the older subgroup dropped to $7.5 \%$ and $4.0 \%$ for saxagliptin $2.5 \mathrm{mg}$ and $5 \mathrm{mg}$, respectively, and to $5.9 \%$ for placebo.

In the initial combination study, reported hypoglycemia was infrequent among older patients (3.0\% with saxagliptin $5 \mathrm{mg}$ plus metformin; $0 \%$ with metformin monotherapy), and there were no cases of confirmed hypoglycemia. No hypoglycemic event required medical assistance. The incidence of hypoglycemic events was similar in older and younger patients.

\section{Discussion}

Decisions regarding the use of antihyperglycemic therapies in the geriatric population should be made with consideration of safety profiles and ease of use. Specifically, sulfonylureas carry a greater risk of hypoglycemia, ${ }^{27}$ whereas thiazolidinediones may increase the risk of peripheral edema, congestive heart failure, ${ }^{28}$ and bladder cancer, ${ }^{29}$ and GLP-1 agonists require subcutaneous injection and are associated with nausea. ${ }^{30}$ The presence of comorbidities and polypharmacy are additional important considerations and potentially limiting factors in the selection of antihyperglycemic therapy for older patients with diabetes. ${ }^{5}$

DPP-4 inhibitors enhance natural glucoregulatory physiology by preventing the rapid degradation of endogenous incretin hormones, GLP-1 and glucose-dependent insulinotropic polypeptide (GIP), that is normally mediated 
Table 3A Glycemic efficacy at 24 weeks in older and younger patients with type 2 diabetes mellitus from five pooled studies of saxagliptin vs placebo as monotherapy and as add-on therapy ${ }^{18-21,24}$

\begin{tabular}{|c|c|c|c|c|c|c|}
\hline & \multicolumn{3}{|l|}{ Age $\geq 65$ years } & \multicolumn{3}{|l|}{ Age $<65$ years } \\
\hline & SAXA $2.5 \mathrm{mg}$ & SAXA 5 mg & PBO & SAXA $2.5 \mathrm{mg}$ & SAXA 5 mg & PBO \\
\hline \multicolumn{7}{|l|}{ Primary endpoint } \\
\hline Change in $\mathrm{HbA}_{\mathrm{Ic}}(\%)$ & $\mathrm{n}=135$ & $\mathrm{n}=138$ & $n=136$ & $n=656$ & $n=723$ & $n=643$ \\
\hline Mean $\mathrm{HbA}_{\mathrm{Ic}}$ at baseline & 8.13 & 8.06 & 7.91 & 8.19 & 8.24 & 8.23 \\
\hline Mean $\mathrm{HbA}_{\mathrm{Ic}}$ at week 24 & 7.44 & 7.29 & 7.91 & 7.63 & 7.55 & 8.22 \\
\hline$\Delta$ & -0.78 & -0.73 & -0.17 & -0.57 & -0.68 & -0.01 \\
\hline $95 \%$ 2-sided $\mathrm{Cl}$ for $\Delta$ & $(-1.05,-0.50)$ & $(-1.04,-0.42)$ & $(-0.45,0.10)$ & $(-0.65,-0.50)$ & $(-0.75,-0.61)$ & $(-0.09,0.07)$ \\
\hline Difference in $\Delta \mathrm{vs} \mathrm{PBO}^{\mathrm{a}}$ & -0.60 & -0.55 & & -0.56 & -0.67 & \\
\hline $\begin{array}{l}95 \% \text { 2-sided } \mathrm{Cl} \text { for difference } \\
\text { in } \Delta \text { vs } \mathrm{PBO}\end{array}$ & $(-0.99,-0.21)$ & $(-0.97,-0.14)$ & & $(-0.67,-0.46)$ & $(-0.77,-0.56)$ & \\
\hline \multicolumn{7}{|l|}{ Secondary endpoints } \\
\hline FPG (mg/dL) & $\mathrm{n}=137$ & $\mathrm{n}=140$ & $\mathrm{n}=135$ & $\mathrm{n}=662$ & $n=731$ & $\mathrm{n}=650$ \\
\hline$\Delta$ & -11.7 & -15.7 & -4.1 & -10.6 & -13.3 & 2.4 \\
\hline Difference in $\Delta \mathrm{vs} \mathrm{PBO}^{\mathrm{a}}$ & -7.6 & -11.6 & & -13.1 & -15.7 & \\
\hline $\begin{array}{l}95 \% \text { 2-sided } \mathrm{Cl} \text { for difference } \\
\text { in } \Delta \text { vs } \mathrm{PBO}\end{array}$ & $(-17.4,2.2)$ & $(-21.4,-1.9)$ & & $(-17.5,-8.6)$ & $(-20.1,-11.3)$ & \\
\hline PPG-AUC ${ }_{0-180}(\mathrm{mg} \cdot \mathrm{min} / \mathrm{dL})$ & $n=109$ & $\mathrm{n}=100$ & $\mathrm{n}=93$ & $\mathrm{n}=504$ & $n=542$ & $n=478$ \\
\hline$\Delta$ & -8332 & -8493 & -3522 & -6659 & -7760 & -1387 \\
\hline Difference in $\Delta$ vs $\mathrm{PBO}^{\mathrm{a}}$ & -4810 & -4970 & & -5272 & -6373 & \\
\hline $\begin{array}{l}95 \% \text { 2-sided } \mathrm{Cl} \text { for difference } \\
\text { in } \Delta \text { vs } \mathrm{PBO}\end{array}$ & $(-7697,-1923)$ & $(-7916,-2024)$ & & $(-6577,-3967)$ & $(-7659,-5088)$ & \\
\hline PPG-I 20 (mg/dL) & $\mathrm{n}=112$ & $\mathrm{n}=105$ & $\mathrm{n}=97$ & $n=520$ & $n=561$ & $\mathrm{n}=489$ \\
\hline$\Delta$ & -56.0 & -54.0 & -20.98 & -45.6 & -50.7 & -7.7 \\
\hline Difference in $\Delta$ vs $\mathrm{PBO}^{\mathrm{a}}$ & -35.0 & -33.0 & & -37.9 & -43.1 & \\
\hline $\begin{array}{l}95 \% \text { 2-sided } \mathrm{Cl} \text { for difference } \\
\text { in } \Delta \text { vs } \mathrm{PBO}\end{array}$ & $(-55.3,-14.8)$ & $(-53.5,-12.4)$ & & $(-47.1,-28.7)$ & $(-52.1,-34.0)$ & \\
\hline Glycemic response & $\mathrm{n}=135$ & $\mathrm{n}=138$ & $\mathrm{n}=136$ & $\mathrm{n}=656$ & $\mathrm{n}=724$ & $\mathrm{n}=643$ \\
\hline$\%$ achieving $\mathrm{HbA}_{\mathrm{Ic}}<7.0 \%$ & $37.8 \%$ & $44.9 \%$ & $16.9 \%$ & $32.5 \%$ & $34.5 \%$ & $19.0 \%$ \\
\hline Difference vs $\mathrm{PBO}^{\mathrm{a}}$ & $21.4 \%$ & $25.9 \%$ & & $13.3 \%$ & $14.7 \%$ & \\
\hline 95\% 2-sided $\mathrm{Cl}$ for difference vs PBO & $(9.8,32.9)$ & $(14.5,37.3)$ & & $(8.6,18.0)$ & $(9.8,19.6)$ & \\
\hline
\end{tabular}

Note: aBaseline-adjusted mean change with saxagliptin - baseline-adjusted mean change with control.

Abbreviations: $\Delta$, baseline-adjusted mean change from baseline to week 24; $\mathrm{Cl}$, confidence interval; $\mathrm{FPG}$, fasting plasma glucose; $\mathrm{HbA}$, glycated hemoglobin; PBO, placebo; PPG, postprandial glucose; PPG-120, PPG change from baseline at 120 minutes in oral glucose tolerance test (OGTT); PPG-AUC (I $_{0}$, postprandial glucose-area under the curve for the period 0-180 minutes on OGTT; SAXA, saxagliptin.

by the enzyme DPP-4. These incretin hormones, released from the gut upon food intake, ${ }^{31,32}$ lower blood glucose by stimulating the pancreas to synthesize and secrete insulin while decreasing glucagon release. Because these actions are glucose-dependent and their effects diminish as postprandial glucose drops back toward normal levels, ${ }^{31,33}$ the risk of hypoglycemia with DPP-4 inhibitors is minimal. Together with the fact that they are orally administered, effective, and well tolerated, this makes DPP-4 inhibitors a potentially useful therapeutic option in elderly patients with T2DM. ${ }^{9}$ The joint American Association of Clinical Endocrinologists and American College of Endocrinology treatment algorithm recommends DPP-4 inhibitors as monotherapy in patients with $\mathrm{HbA}_{1 \mathrm{c}}$ levels of $6.5 \%$ to $7.5 \%$ or as a preferred combination therapy with metformin for patients with $\mathrm{HbA}_{1 \mathrm{c}}$ levels $\geq 7.6 \% .^{34}$
In the present post hoc analysis of the outcomes in older patients with T2DM, the DPP-4 inhibitor saxagliptin was effective in improving glycemic control, as shown by reductions in $\mathrm{HbA}_{1 \mathrm{c}}$, FPG, PPG-AUC ${ }_{0-180}$, and PPG-120 and by an increased proportion of patients achieving the glycemic goal of $\mathrm{HbA}_{1 \mathrm{c}}<7.0 \%$ with saxagliptin versus the comparators (placebo in the five-study pooled analysis or metformin monotherapy in the initial combination study). In the five-study pooled analysis and the initial combination study, patients older and younger than 65 years showed greater improvements in all glycemic parameters with saxagliptin than with comparators. The results were generally similar in older and younger patients except in the initial combination study, wherein the difference in adjusted mean change in $\mathrm{HbA}_{1 \mathrm{c}}$ with saxagliptin plus metformin versus metformin monotherapy was greater in older patients $(-1.22 \%)$ 
Table 3B Glycemic efficacy at 24 weeks in older and younger patients with type 2 diabetes mellitus from a study of saxagliptin 5 mg as initial combination therapy with metformin vs metformin monotherapy ${ }^{22}$

\begin{tabular}{|c|c|c|c|c|}
\hline & \multicolumn{2}{|l|}{ Age $\geq 65$ years } & \multicolumn{2}{|l|}{ Age $<65$ years } \\
\hline & SAXA 5 mg + MET & MET & SAXA $5 \mathrm{mg}+$ MET & MET \\
\hline \multicolumn{5}{|l|}{ Primary endpoint } \\
\hline Change in $\mathrm{HbA}_{\mathrm{Ic}}(\%)$ & $\mathrm{n}=33$ & $\mathrm{n}=36$ & $\mathrm{n}=273$ & $\mathrm{n}=277$ \\
\hline Mean $\mathrm{HbA}_{\mathrm{Ic}}$ at baseline & 9.18 & 8.87 & 9.44 & 9.51 \\
\hline Mean $\mathrm{HbA}_{\mathrm{lc}}$ at week 24 & 7.00 & 7.43 & 6.93 & 7.49 \\
\hline$\Delta$ & -2.48 & -1.26 & -2.55 & -2.01 \\
\hline $95 \%$ 2-sided $\mathrm{Cl}$ for $\Delta$ & $(-3.35,-1.60)$ & $(-1.83,-0.68)$ & $(-2.69,-2.40)$ & $(-2.16,-1.87)$ \\
\hline Difference in $\Delta$ vs MET monotherapy ${ }^{\mathrm{a}}$ & -1.22 & & -0.53 & \\
\hline 95\% 2-sided $\mathrm{Cl}$ for difference & $(-2.27,-0.17)$ & & $(-0.74,-0.33)$ & \\
\hline in $\Delta$ vs MET monotherapy & & & & \\
\hline \multicolumn{5}{|l|}{ Secondary endpoints } \\
\hline FPG (mg/dL) & $\mathrm{n}=33$ & $\mathrm{n}=36$ & $\mathrm{n}=282$ & $\mathrm{n}=284$ \\
\hline$\Delta$ & -65.7 & -44.9 & -58.0 & -46.5 \\
\hline Difference in $\Delta$ vs MET monotherapy ${ }^{\mathrm{a}}$ & -20.7 & & -11.5 & \\
\hline 95\% 2-sided $\mathrm{Cl}$ for difference & $(-39.7,-1.8)$ & & $(-18.1,-4.9)$ & \\
\hline \multicolumn{5}{|l|}{ in $\Delta$ vs MET monotherapy } \\
\hline PPG-AUC ${ }_{0-180}(\mathrm{mg} \cdot \mathrm{min} / \mathrm{dL})$ & $\mathrm{n}=10$ & $\mathrm{n}=9$ & $n=132$ & $n=126$ \\
\hline$\Delta$ & -22504 & -6841 & -20736 & -15393 \\
\hline Difference in $\Delta$ vs MET monotherapy ${ }^{\mathrm{a}}$ & -15663 & & -5343 & \\
\hline 95\% 2-sided $\mathrm{Cl}$ for difference & $(-244|3,-69| 3)$ & & $(-7720,-2965)$ & \\
\hline \multicolumn{5}{|l|}{ in $\Delta$ vs MET monotherapy } \\
\hline PPG-I 20 (mg/dL) & $\mathrm{n}=10$ & $\mathrm{n}=9$ & $n=136$ & $n=132$ \\
\hline$\Delta$ & -136.8 & -34.63 & -136.2 & -99.67 \\
\hline Difference in $\Delta$ vs MET monotherapy ${ }^{\mathrm{a}}$ & -102.2 & & -36.5 & \\
\hline 95\% 2-sided $\mathrm{Cl}$ for difference & $(-161.7,-42.7)$ & & $(-52.4,-20.7)$ & \\
\hline \multicolumn{5}{|l|}{ in $\Delta$ vs MET monotherapy } \\
\hline Glycemic response & $\mathrm{n}=33$ & $\mathrm{n}=36$ & $\mathrm{n}=274$ & $\mathrm{n}=278$ \\
\hline$\%$ achieving $\mathrm{HbA}_{\mathrm{lc}}<7.0 \%$ & $57.6 \%$ & $38.9 \%$ & $60.6 \%$ & $41.4 \%$ \\
\hline Difference vs MET monotherapy & $18.7 \%$ & & $19.2 \%$ & \\
\hline $95 \%$ 2-sided $\mathrm{Cl}$ for difference vs & $(-5.7,40.6)$ & & $(10.9,27.3)$ & \\
\hline MET monotherapy & & & & \\
\hline
\end{tabular}

Note: ${ }^{a}$ Baseline-adjusted mean change with saxagliptin - baseline-adjusted mean change with control.

Abbreviations: $\Delta$, baseline-adjusted mean change from baseline to week 24; $\mathrm{Cl}$, confidence interval; $\mathrm{FPG}$, fasting plasma glucose; $\mathrm{HbA}_{\mathrm{Ic}}$, glycated hemoglobin; PBO, placebo; PPG, postprandial glucose; PPG-120, PPG change from baseline at 120 minutes in oral glucose tolerance test (OGTT); PPG-AUC (I80, Postprandial glucose-area under the curve for the period 0-180 minutes on OGTT; SAXA, saxagliptin.

than in younger patients $(-0.53 \%)$; there were no significant treatment-by-age interactions. Saxagliptin treatment was well tolerated and was associated with a low incidence of hypoglycemic events.

These results are important given that the Action to Control Cardiovascular Risk in Diabetes (ACCORD) $)^{35}$ and Action in Diabetes and Vascular Disease: Preterax and Diamicron Modified Release Controlled Evaluation (ADVANCE) ${ }^{36}$ trials showed an association between hypoglycemia (glucose $<50 \mathrm{mg} / \mathrm{dL}$ ) and age, and ACCORD ${ }^{37}$ linked hypoglycemia to an increased risk of death, prompting the American Diabetes Association and the European Association for the Study of Diabetes to note that it is especially important to avoid treatment-related hypoglycemia in elderly patients. ${ }^{5}$ Hypoglycemia can impair judgment, behavior, and performance of physical tasks $;{ }^{38}$ such adverse effects can interfere with treatment adherence, especially in elderly patients.

Concern about iatrogenic hypoglycemia can be a barrier to good glycemic control. Because the antihyperglycemic effects of the DPP-4 inhibitors are glucose dependent, the risk of hypoglycemia is low..$^{31,33,39}$ In contrast, sulfonylureas and meglitinides stimulate insulin secretion independent of glucose concentrations, and sulfonylureas in particular are associated with a higher risk of hypoglycemia, ${ }^{40}$ including use in combination with a DPP-4 inhibitor. ${ }^{21,41}$ Thus, sulfonylureas should be used with particular caution in elderly patients.

The results from the present post hoc analysis are generally consistent with the results of another pooled analysis of data on saxagliptin in older patients that was limited to patients treated with saxagliptin $5 \mathrm{mg}$ in the five 
Table 4A Adverse events in older and younger patients with type 2 diabetes mellitus from five pooled studies of saxagliptin vs placebo as monotherapy and as add-on therapy ${ }^{18-21,24}$

\begin{tabular}{|c|c|c|c|c|c|c|}
\hline & \multicolumn{3}{|l|}{ Age $\geq 65$ years } & \multicolumn{3}{|l|}{ Age $<65$ years } \\
\hline & $\begin{array}{l}\text { SAXA } 2.5 \mathrm{mg} \\
\mathrm{n}=149\end{array}$ & $\begin{array}{l}\text { SAXA } 5 \mathrm{mg} \\
\mathrm{n}=142\end{array}$ & $\begin{array}{l}\text { PBO } \\
n=137\end{array}$ & $\begin{array}{l}\text { SAXA } 2.5 \mathrm{mg} \\
\mathrm{n}=733\end{array}$ & $\begin{array}{l}\text { SAXA } 5 \mathrm{mg} \\
\mathrm{n}=740\end{array}$ & $\begin{array}{l}\text { PBO } \\
n=662\end{array}$ \\
\hline \multicolumn{7}{|c|}{ Summary of AEs (including hypoglycemia), n (\%) } \\
\hline$\geq \mathrm{IAE}$ & $107(71.8)$ & $101(7 \mid .1)$ & III (8I.0) & $528(72.0)$ & $536(72.4)$ & $453(68.4)$ \\
\hline$\geq \mathrm{I}$ treatment-related $\mathrm{AE}$ & $25(16.8)$ & $30(21.1)$ & $27(19.7)$ & $130(17.7)$ & $135(18.2)$ & $107(16.2)$ \\
\hline$\geq I S A E$ & $8(5.4)$ & $4(2.8)$ & $7(5.1)$ & $23(3.1)$ & $26(3.5)$ & $20(3.0)$ \\
\hline$\geq \mathrm{I}$ treatment-related SAE & 0 & 0 & 0 & $2(0.3)$ & $\mathrm{I}(0 . \mathrm{l})$ & $\mathrm{I}(0.2)$ \\
\hline Discontinuations due to AEs & $4(2.7)$ & $6(4.2)$ & $3(2.2)$ & $15(2.0)$ & $23(3.1)$ & II (I.7) \\
\hline Discontinuations due to SAEs & 0 & I (0.7) & $\mathrm{I}(0.7)$ & $5(0.7)$ & $\mathrm{I}(0.1)$ & $4(0.6)$ \\
\hline Deaths & $\mathrm{I}(0.7)$ & 0 & 0 & $\mathrm{I}(0.1)$ & 0 & $2(0.3)$ \\
\hline \multicolumn{7}{|c|}{ AEs $s^{a}$ (excluding hypoglycemia) occurring in $\geq 5 \%$ of patients in any treatment group, $n(\%)$} \\
\hline Urinary tract infection & $8(5.4)$ & $8(5.6)$ & $8(5.8)$ & $37(5.0)$ & $52(7.0)$ & $4 I(6.2)$ \\
\hline Nasopharyngitis & $7(4.7)$ & $7(4.9)$ & $10(7.3)$ & $43(5.9)$ & $42(5.7)$ & $44(6.6)$ \\
\hline Upper respiratory tract infection & $7(4.7)$ & $6(4.2)$ & $10(7.3)$ & $55(7.5)$ & $62(8.4)$ & $51(7.7)$ \\
\hline Influenza & $5(3.4)$ & $4(2.8)$ & II (8.0) & $29(4.0)$ & $26(3.5)$ & $24(3.6)$ \\
\hline Bronchitis & $5(3.4)$ & $2(1.4)$ & $7(5.1)$ & $19(2.6)$ & $17(2.3)$ & $7(1.1)$ \\
\hline Back pain & $2(1.3)$ & II (7.7) & $6(4.4)$ & $31(4.2)$ & $27(3.6)$ & $35(5.3)$ \\
\hline Arthralgia & $9(6.0)$ & $6(4.2)$ & $5(3.6)$ & $25(3.4)$ & $26(3.5)$ & $19(2.9)$ \\
\hline Pain in extremity & $3(2.0)$ & $3(2.1)$ & $7(5.1)$ & $26(3.5)$ & $24(3.2)$ & $26(3.9)$ \\
\hline Diarrhea & $9(6.0)$ & $6(4.2)$ & $10(7.3)$ & $44(6.0)$ & $30(4.1)$ & $39(5.9)$ \\
\hline Headache & $9(6.0)$ & $5(3.5)$ & $9(6.6)$ & $48(6.5)$ & $52(7.0)$ & $38(5.7)$ \\
\hline Dizziness & $5(3.4)$ & $4(2.8)$ & $10(7.3)$ & II (I.5) & $17(2.3)$ & $19(2.9)$ \\
\hline Hypertension & $6(4.0)$ & $10(7.0)$ & $4(2.9)$ & $31(4.2)$ & $25(3.4)$ & $24(3.6)$ \\
\hline Cough & $5(3.4)$ & $3(2.1)$ & II (8.0) & $30(4.1)$ & $21(2.8)$ & $25(3.8)$ \\
\hline \multicolumn{7}{|l|}{ Hypoglycemia, n (\%) } \\
\hline Reported ${ }^{b}$ & $14(9.4)$ & $9(6.3)$ & II (8.0) & $53(7.2)$ & $60(8.1)$ & $43(6.5)$ \\
\hline Confirmed $^{c}$ & I (0.7) & 0 & $\mathrm{I}(0.7)$ & $6(0.8)$ & $4(0.5)$ & $2(0.3)$ \\
\hline $\begin{array}{l}\text { Hypoglycemia excluding study of } \\
\text { saxagliptin add-on to glyburide, } n(\%)\end{array}$ & $\mathrm{n}=106$ & $\mathrm{n}=100$ & $\mathrm{n}=85$ & $\mathrm{n}=528$ & $n=529$ & $n=447$ \\
\hline Reported ${ }^{b}$ & $8(7.5)$ & $4(4.0)$ & $5(5.9)$ & $23(4.4)$ & $26(4.9)$ & $17(3.8)$ \\
\hline Confirmed $^{c}$ & 0 & 0 & 0 & $2(0.4)$ & 0 & $\mathrm{I}(0.2)$ \\
\hline
\end{tabular}

Notes: aPresented by preferred term in order of system order class, in the subgroup $\geq 65$ years of age; 'bigns or symptoms of hypoglycemia, with or without documented blood glucose levels; ' finger stick glucose $\leq 50 \mathrm{mg} / \mathrm{dL}$, with associated symptoms.

Abbreviations: AEs, adverse events; PBO, placebo; SAEs, serious AEs; SAXA, saxagliptin.

placebo-controlled core saxagliptin studies. ${ }^{25}$ The previous study reported a change in $\mathrm{HbA}_{1 \mathrm{c}}$ of $-0.73 \%$ (from baseline mean $8.1 \%$ ) and a low incidence of AEs comparable with that of placebo. The present results are also comparable with outcomes reported in studies of other DPP-4 inhibitors. In a 24-week study, the adjusted mean change from baseline $\mathrm{HbA}_{1 \mathrm{c}}$ was $-0.64 \%$ in drug-naïve elderly patients treated with vildagliptin. ${ }^{42}$ As add-on to metformin in adult patients (all ages), vildagliptin yielded a change from baseline $\mathrm{HbA}_{1 \mathrm{c}}$ of $-0.44 \%{ }^{43}$ The pooled data from five earlier trials of vildagliptin monotherapy showed a mean change from baseline $\mathrm{HbA}_{1 \mathrm{c}}$ of $-1.2 \%$ in drug-naïve patients $\geq 65$ years, which was comparable with the reduction of $1.0 \%$ in patients $<65$ years. ${ }^{13}$ In a 24 -week trial of sitagliptin monotherapy in elderly patients with $\mathrm{T} 2 \mathrm{DM}$, the mean change from baseline in $\mathrm{HbA}_{1 \mathrm{c}}$ was $-0.7 \%$, the incidence of AEs was comparable with that of a placebo, and there were no episodes of hypoglycemia. ${ }^{16}$ Pooled data from the trials of the investigational DPP-4 inhibitor alogliptin, used as monotherapy or dual therapy, show changes from baseline in $\mathrm{HbA}_{1 \mathrm{c}}$ of $-0.7 \%$ to $-0.8 \%$ in elderly patients and $-0.5 \%$ to $-0.6 \%$ in younger patients. ${ }^{12}$ For linagliptin, no differences in safety and effectiveness were reported in elderly versus younger patients. ${ }^{44}$ In perspective, the present analysis suggests that saxagliptin as monotherapy, combination therapy, and initial combination therapy with metformin improves glycemic control in older patients to an extent comparable with that seen with other DDP-4 inhibitors.

With respect to safety and tolerability, the present analysis demonstrated that saxagliptin was generally well tolerated in older patients; the overall incidence of AEs was similar in the older and younger subgroups in the pooled 
Table 4B Adverse events in older and younger patients with type 2 diabetes mellitus from a study of saxagliptin 5 mg as initial combination therapy with metformin vs metformin monotherapy ${ }^{22}$

\begin{tabular}{|c|c|c|c|c|}
\hline & \multicolumn{2}{|c|}{ Age $\geq 65$ years } & \multicolumn{2}{|l|}{ Age $<65$ years } \\
\hline & $\begin{array}{l}\text { SAXA + MET } \\
n=33\end{array}$ & $\begin{array}{l}\text { MET } \\
n=36\end{array}$ & $\begin{array}{l}\text { SAXA + MET } \\
n=287\end{array}$ & $\begin{array}{l}\text { MET } \\
n=292\end{array}$ \\
\hline \multicolumn{5}{|c|}{ Summary of AEs (including hypoglycemia), n (\%) } \\
\hline$\geq I A E$ & $20(60.6)$ & $18(50.0)$ & $157(54.7)$ & $174(59.6)$ \\
\hline$\geq \mathrm{I}$ treatment-related $\mathrm{AE}$ & $5(15.2)$ & $6(16.7)$ & $28(9.8)$ & $53(18.2)$ \\
\hline$\geq I \mathrm{SAE}$ & I (3.0) & $2(5.6)$ & $7(2.4)$ & $6(2.1)$ \\
\hline$\geq I$ treatment-related SAE & I (3.0) & 0 & 0 & 0 \\
\hline Discontinuations due to AEs & I (3.0) & I (2.8) & $7(2.4)$ & $10(3.4)$ \\
\hline Discontinuations due to SAEs & 0 & 0 & $\mathrm{I}(0.3)$ & $\mathrm{I}(0.3)$ \\
\hline Deaths & 0 & I (2.8) & 0 & $2(0.7)$ \\
\hline \multicolumn{5}{|c|}{$\mathrm{AEs}^{\mathrm{a}}$ (excluding hypoglycemia) occurring in $\geq 5 \%$ of patients in any treatment group, $n(\%)$} \\
\hline Upper respiratory tract infection & I (3.0) & 0 & $10(3.5)$ & $6(2.1)$ \\
\hline Influenza & $2(6.1)$ & 0 & $9(3.1)$ & II (3.8) \\
\hline Nasopharyngitis & 0 & 0 & $22(7.7)$ & $13(4.5)$ \\
\hline Urinary tract infection & I (3.0) & 0 & $7(2.4)$ & $16(5.5)$ \\
\hline Diarrhea & $3(9.1)$ & $3(8.3)$ & $19(6.6)$ & $21(7.2)$ \\
\hline Dyspepsia & $2(6.1)$ & 0 & $6(2.1)$ & $4(1.4)$ \\
\hline Gastritis & $2(6.1)$ & 0 & $7(2.4)$ & $6(2.1)$ \\
\hline Headache & $4(12.1)$ & $\mathrm{I}(2.8)$ & $20(7.0)$ & $16(5.5)$ \\
\hline Hypertension & I (3.0) & I (2.8) & $14(4.9)$ & $10(3.4)$ \\
\hline Hypertensive crisis & $2(6.1)$ & $2(5.6)$ & $2(0.7)$ & 0 \\
\hline Anemia & $2(6.1)$ & 0 & $6(2.1)$ & $5(1.7)$ \\
\hline \multicolumn{5}{|l|}{ Hypoglycemia, n (\%) } \\
\hline Reported ${ }^{b}$ & I (3.0) & 0 & $10(3.5)$ & $13(4.5)$ \\
\hline Confirmed $^{c}$ & 0 & 0 & 0 & $\mathrm{I}(0.3)$ \\
\hline
\end{tabular}

Notes: aPresented by preferred term in order of system order class, in the older ( $\geq 65$ years) subgroup; bsigns or symptoms of hypoglycemia, with or without documented blood glucose levels; ' finger stick glucose $\leq 50 \mathrm{mg} / \mathrm{dL}$, with associated symptoms.

Abbreviations: AEs, adverse events; MET, metformin; PBO, placebo; SAEs, serious AEs; SAXA, saxagliptin.

analysis and also in the initial combination study, with no notable differences between the subgroups and the overall populations of the individual studies. A particular safety concern in elderly patients with T2DM is renal impairment, which may develop independently or secondarily to diabetes. A study of saxagliptin in adult patients (all ages) with T2DM and renal impairment revealed that the use of $2.5 \mathrm{mg}$ saxagliptin resulted in no treatment-related decline in renal function..$^{45}$ For patients with mild and moderate renal impairment, there is no need for dose adjustment. For patients with severe renal impairment or end-stage renal disease, the $2.5 \mathrm{mg}$ dose of saxagliptin is recommended. ${ }^{26}$ In the present subanalysis, the mean baseline creatinine clearance rate of the older patients ranged between 80 and $84 \mathrm{~mL} / \mathrm{min}$, and no safety and tolerability issues were noted with the 2.5 -mg or 5-mg dose. Further efficacy and tolerability data are expected in 2013 from an ongoing study of saxagliptin versus the sulfonylurea glimepiride in elderly patients with T2DM inadequately controlled on metformin monotherapy (ClinicalTrials.gov identifier: NCT01006603).
Certain statistical limitations should be considered when assessing the results of this analysis. Although outcomes with saxagliptin appeared similar for patients older and younger than 65 years, the fact that the older subset contained notably fewer patients than the younger subset and that the older subset mainly comprised patients aged 65 to 75 years of age limits the ability to draw conclusions about possible age-related effects.

\section{Conclusion}

In T2DM patients aged $\geq 65$ years, the majority of whom reported a background of polypharmacy, saxagliptin was superior to placebo when used as monotherapy in treatmentnaïve patients and as add-on to another oral antidiabetic drug. The improvement in glycemic control was similar to that seen in younger patients. Saxagliptin used in initial combination therapy with metformin was also superior to metformin monotherapy in antidiabetic drug-naïve older patients, many of whom were taking multiple concomitant medications, and the improvement in glycemic measures with saxagliptin was numerically greater in the older group than in 
the younger group. In view of its favorable profile of efficacy and tolerability and low risk of hypoglycemia, saxagliptin is an attractive treatment option to improve glycemic control in elderly patients with T2DM.

\section{Acknowledgments}

The authors thank Mark Donovan, PhD, of Bristol-Myers Squibb for statistical assistance and critical review of the manuscript.

\section{Disclosure}

The authors are employees of Bristol-Myers Squibb. This study was funded by Bristol-Myers-Squibb, Plainsboro, NJ, and AstraZeneca, Wilmington, DE. Authors are employees of these companies and participated in the study design, the collection and interpretation of data, and in the drafting of the manuscript at all stages.

Medical writing support was provided by Paul Ruest, PhD, and Jennifer Ciafullo, MPH, Quintiles Medical Communications, Parsippany, NJ; and Susan DeRocco, PhD, and Steven Tiger, PA, Complete Healthcare Communications, Inc., Chadds Ford, PA, with funding provided by BristolMyers-Squibb and AstraZeneca.

The authors report no other conflicts of interest.

\section{References}

1. aoa.gov [homepage on the Internet]. Projected future growth of the older population. Administration on Aging (Department of Health and Human Services); 2010 [updated June 23, 2010; cited October 4, 2012]. Available from: http://www.aoa.gov/AoARoot/Aging_Statistics/future_growth/ future_growth.aspx\#age. Accessed February 24, 2013.

2. Centers for Disease Control and Prevention. National Diabetes Fact Sheet: National Estimates and General Information on Diabetes and Prediabetes in the United States, 2011. Atlanta: US Centers for Disease Control and Prevention (Department of Health and Human Services); 2011. Available from: http://www.cdc.gov/diabetes/pubs/pdf/ndfs_2011. pdf. Accessed December 12, 2012.

3. Brown AF, Mangione CM, Saliba D, Sarkisian CA; California Healthcare Foundation/American Geriatrics Society Panel on Improving Care for Elders with Diabetes. Guidelines for improving the care of the older person with diabetes mellitus. J Am Geriatr Soc. 2003; 51(Suppl Guidelines 5):S265-S280.

4. Sinclair AJ, Conroy SP, Bayer AJ. Impact of diabetes on physical function in older people. Diabetes Care. 2008;31(2):233-235.

5. Inzucchi SE, Bergenstal RM, Buse JB, et al; American Diabetes Association (ADA); European Association for the Study of Diabetes (EASD). Management of hyperglycemia in type 2 diabetes: a patient-centered approach: position statement of the American Diabetes Association (ADA) and the European Association for the Study of Diabetes (EASD). Diabetes Care. 2012;35(6):1364-1379.

6. Schwartz AV, Vittinghoff E, Sellmeyer DE, et al; Health, Aging, and Body Composition Study. Diabetes-related complications, glycemic control, and falls in older adults. Diabetes Care. 2008;31(3):391-396.

7. Maraldi C, Volpato S, Penninx BW, et al. Diabetes mellitus, glycemic control, and incident depressive symptoms among 70- to 79-year-old persons: the health, aging, and body composition study. Arch Intern Med. 2007;167(11):1137-1144.
8. Munshi M, Grande L, Hayes M, et al. Cognitive dysfunction is associated with poor diabetes control in older adults. Diabetes Care. 2006; 29(8):1794-1799.

9. Neumiller JJ, Wood L, Campbell RK. Dipeptidyl peptidase-4 inhibitors for the treatment of type 2 diabetes mellitus. Pharmacotherapy. 2010;30(5):463-484.

10. Handelsman Y, Mechanick JI, Blonde L, et al; AACE Task Force for Developing Diabetes Comprehensive Care Plan. American Association of Clinical Endocrinologists medical guidelines for clinical practice for developing a diabetes mellitus comprehensive care plan. Endocr Pract. 2011;17(Suppl 2):S1-S53.

11. Nathan DM, Buse JB, Davidson MB, et al; American Diabetes Association; European Association for Study of Diabetes. Medical management of hyperglycemia in type 2 diabetes: a consensus algorithm for the initiation and adjustment of therapy: a consensus statement of the American Diabetes Association and the European Association for the Study of Diabetes. Diabetes Care. 2009;32(1):193-203.

12. Pratley RE, McCall T, Fleck PR, Wilson CA, Mekki Q. Alogliptin use in elderly people: a pooled analysis from phase 2 and 3 studies. $J \mathrm{Am}$ Geriatr Soc. 2009;57(11):2011-2019.

13. Pratley RE, Rosenstock J, Pi-Sunyer FX, et al. Management of type 2 diabetes in treatment-naive elderly patients: benefits and risks of vildagliptin monotherapy. Diabetes Care. 2007;30(12): 3017-3022.

14. Halimi S, Raccah D, Schweizer A, Dejager S. Role of vildagliptin in managing type 2 diabetes mellitus in the elderly. Curr Med Res Opin. 2010;26(7):1647-1656.

15. Schweizer A, Dejager S, Foley JE, Shao Q, Kothny W. Clinical experience with vildagliptin in the management of type 2 diabetes in a patient population $\geq 75$ years: a pooled analysis from a database of clinical trials. Diabetes Obes Metab. 2011;13(1):55-64.

16. Barzilai N, Guo H, Mahoney EM, et al. Efficacy and tolerability of sitagliptin monotherapy in elderly patients with type 2 diabetes: a randomized, double-blind, placebo-controlled trial. Curr Med Res Opin. 2011;27(5):1049-1058.

17. US Food and Drug Administration. NDA Approval [Onglyza New Drug Approval]. Silver Spring: US Food and Drug Administration; 2009. Available from: http://www.accessdata.fda.gov/drugsatfda_docs/ appletter/2009/022350s0001tr.pdf. Accessed October 19, 2011.

18. Rosenstock J, Aguilar-Salinas C, Klein E, Nepal S, List J, Chen R; CV181-011 Study Investigators. Effect of saxagliptin monotherapy in treatment-naïve patients with type 2 diabetes. Curr Med Res Opin. 2009;25(10):2401-2411

19. Hollander P, Li J, Allen E, Chen R; CV181-013 Investigators. Saxagliptin added to a thiazolidinedione improves glycemic control in patients with type 2 diabetes and inadequate control on thiazolidinedione alone. J Clin Endocrinol Metab. 2009;94(12):4810-4819.

20. DeFronzo RA, Hissa MN, Garber AJ, et al; Saxagliptin 014 Study Group. The efficacy and safety of saxagliptin when added to metformin therapy in patients with inadequately controlled type 2 diabetes with metformin alone. Diabetes Care. 2009;32(9):1649-1655.

21. Chacra AR, Tan GH, Apanovitch A, Ravichandran S, List J, Chen R; CV181-040 Investigators. Saxagliptin added to a submaximal dose of sulphonylurea improves glycaemic control compared with uptitration of sulphonylurea in patients with type 2 diabetes: a randomised controlled trial. Int J Clin Pract. 2009;63(9):1395-1406.

22. Jadzinsky M, Pfützner A, Paz-Pacheco E, Xu Z, Allen E, Chen R; CV181-039 Investigators. Saxagliptin given in combination with metformin as initial therapy improves glycaemic control in patients with type 2 diabetes compared with either monotherapy: a randomized controlled trial. Diabetes Obes Metab. 2009;11(6):611-622.

23. Kulasa K, Edelman S. Saxagliptin: the evidence for its place in the treatment of type 2 diabetes mellitus. Core Evid. 2010;5:23-37.

24. Frederich R, McNeill R, Berglind N, Fleming D, Chen R. The efficacy and safety of the dipeptidyl peptidase-4 inhibitor saxagliptin in treatment-naïve patients with type 2 diabetes mellitus: a randomized controlled trial. Diabetol Metab Syndr. 2012;4(1):36. 
25. Doucet J, Chacra A, Maheux P, Lu J, Harris S, Rosenstock J. Efficacy and safety of saxagliptin in older patients with type 2 diabetes mellitus. Curr Med Res Opin. 2011;27(4):863-869.

26. Onglyza ${ }^{\circledR}$ (saxagliptin) [prescribing information]. Princeton: BristolMyers Squibb Company, 2012.

27. Bennett WL, Maruthur NM, Singh S, et al. Comparative effectiveness and safety of medications for type 2 diabetes: an update including new drugs and 2-drug combinations. Ann Intern Med. 2011;154(9): $602-613$.

28. Filion KB, Joseph L, Boivin JF, Suissa S, Brophy JM. Thiazolidinediones and the risk of incident congestive heart failure among patients with type 2 diabetes mellitus. Pharmacoepidemiol Drug Saf. 2011;20(8):785-796.

29. Lewis JD, Ferrara A, Peng T, et al. Risk of bladder cancer among diabetic patients treated with pioglitazone: interim report of a longitudinal cohort study. Diabetes Care. 2011;34(4):916-922.

30. Gallwitz B. Benefit-risk assessment of exenatide in the therapy of type 2 diabetes mellitus. Drug Saf. 2010;33(2):87-100.

31. Drucker DJ. Enhancing incretin action for the treatment of type 2 diabetes. Diabetes Care. 2003;26(10):2929-2940.

32. Drucker DJ. The biology of incretin hormones. Cell Metab. 2006;3(3): 153-165.

33. Drucker DJ, Nauck MA. The incretin system: glucagon-like peptide-1 receptor agonists and dipeptidyl peptidase- 4 inhibitors in type 2 diabetes. Lancet. 2006;368(9548):1696-1705.

34. Rodbard HW, Jellinger PS, Davidson JA, et al. Statement by an American Association of Clinical Endocrinologists/American College of Endocrinology consensus panel on type 2 diabetes mellitus: an algorithm for glycemic control. Endocr Pract. 2009;15(6):540-559.

35. Miller ME, Bonds DE, Gerstein HC, et al; ACCORD Investigators. The effects of baseline characteristics, glycaemia treatment approach, and glycated haemoglobin concentration on the risk of severe hypoglycaemia: post hoc epidemiological analysis of the ACCORD study. BMJ. 2010;340:b5444.

36. Zoungas S, Chalmers J, Kengne AP, et al. The efficacy of lowering glycated haemoglobin with a gliclazide modified release-based intensive glucose lowering regimen in the ADVANCE trial. Diabetes Res Clin Pract. 2010;89(2):126-133.
37. Bonds DE, Miller ME, Bergenstal RM, et al. The association between symptomatic, severe hypoglycaemia and mortality in type 2 diabetes: retrospective epidemiological analysis of the ACCORD study. BMJ. 2010;340:b4909.

38. Cryer PE. The barrier of hypoglycemia in diabetes. Diabetes. 2008; 57(12):3169-3176.

39. Ahrén B, Foley JE, Ferrannini E, et al. Changes in prandial glucagon levels after a 2-year treatment with vildagliptin or glimepiride in patients with type 2 diabetes inadequately controlled with metformin monotherapy. Diabetes Care. 2010;33(4):730-732.

40. Phung OJ, Scholle JM, Talwar M, Coleman CI. Effect of noninsulin antidiabetic drugs added to metformin therapy on glycemic control, weight gain, and hypoglycemia in type 2 diabetes. JAMA. 2010;303(14): 1410-1418.

41. UK Prospective Diabetes Study (UKPDS) Group. Intensive bloodglucose control with sulphonylureas or insulin compared with conventional treatment and risk of complications in patients with type 2 diabetes (UKPDS 33). Lancet. 1998;352(9131):837-853.

42. Schweizer A, Dejager S, Bosi E. Comparison of vildagliptin and metformin monotherapy in elderly patients with type 2 diabetes: a 24-week, double-blind, randomized trial. Diabetes Obes Metab. 2009;11(8):804-812.

43. Ferrannini E, Fonseca V, Zinman B, et al. Fifty-two-week efficacy and safety of vildagliptin vs. glimepiride in patients with type 2 diabetes mellitus inadequately controlled on metformin monotherapy. Diabetes Obes Metab. 2009;11(2):157-166.

44. Tradjenta ${ }^{\mathrm{TM}}$ (linagliptin) [prescribing information]. Ridgefield: Boehringer Ingelheim Pharmaceuticals, Inc.; 2011.

45. Nowicki M, Rychlik I, Haller H, Warren ML, Suchower L, GauseNilsson I; D1680C00007 Investigators. Saxagliptin improves glycaemic control and is well tolerated in patients with type 2 diabetes mellitus and renal impairment. Diabetes Obes Metab. 2011;13(6):523-532.
Clinical Interventions in Aging

\section{Publish your work in this journal}

Clinical Interventions in Aging is an international, peer-reviewed journal focusing on evidence-based reports on the value or lack thereof of treatments intended to prevent or delay the onset of maladaptive correlates of aging in human beings. This journal is indexed on PubMed Central, MedLine, the American Chemical Society's 'Chemical Abstracts

\section{Dovepress}

Service' (CAS), Scopus and the Elsevier Bibliographic databases. The manuscript management system is completely online and includes a very quick and fair peer-review system, which is all easy to use. Visit http://www.dovepress.com/testimonials.php to read real quotes from published authors. 